\title{
DESCRIPTIUE STUDY OF HONORIFIC USE IN KOREAN EMAIL DISCOURSE
}

\author{
Jaegu Kim \\ Sekolah Pelita Harapan, Lippo Cikarang, Jakarta \\ kwilliam67@gmail.com
}

First received: 22 March $2016 \quad$ Final proof received: 13 July 2016

\begin{abstract}
It is a relatively new field that examines how Korean culture affects Korean language use in terms of age difference in a corpus of computer mediated email discourse. The purpose of this descriptive study and experiment is to prove the close relationship between Korean language and culture. This paper shows the descriptive study of Korean culture in relation to language use. Korean culture acknowledges an inherent hierarchy with regard to age, and considers [+age] as relating socially to [+power]. When younger Koreans converse with older ones, they express different morpho-syntactic patterns, which is an age complex. The main task of the experiment was to examine the way through which the age complex is reflected by Korean honorific linguistic system in email discourse. I asked 15 Korean native speakers between the ages of 20 to 25 to write emails expressing an impositive request to [+age (46-50 years old)], [-age (below 25 years old)] and [=age] recipients. The results show significant differences in the use of grammatical features in emails written to [+age] recipients, as compared to emails written to [-age] and [=age] recipients. The implication of the findings is that the cultural values that are attached to age and aging in the Korean society affects Koreans' language use, which means Korean language and culture are closely intermingled.
\end{abstract}

Keywords: age, email, discourse, honorific, culture, language, Korean

This study will discuss the relationship between Korean cultural and linguistic phenomena as shown in a computer mediated discourse (CMD), email, where primarily spoken forms of language are used to accomplish conversational communication in the absence of direct physical and contextual signs such as facial expressions or gestures. Studies of CMD constitute a relatively new field, and digital discourse including email is one of the venues that have been actively studied only in recent years (Georgakopoulou \& Tereza, 2015; Thurlow \& Kristine, 2011; Bjørge, 2007; Graham, 2007; Hatipoğlu, 2007; Chen, 2006). Email discourse provides a good data source to see both written and spoken cultural behaviors at the same time (Spilioti, 2011; Bjørge, 2007). Email discourse is engaged in by a great number of users in a huge worldwide network (Crystal, 2005, 2001, 1997). Examining email discourse within the scope of different linguistic and cultural traditions provides a means to explore communication patterns that demonstrate diverse cultural thought patterns and linguistic patterns in use.

This study will show that Koreans' thoughts about age which is an age complex are reflected in Koreans' linguistic features in terms of [+age] relationship, which may or may not be found in those of speakers of other languages. This present study consists of two main tasks, descriptive study and experiment, to build the argument that Koreans' thought about age and Korean language use affect each other in a close relationship. For this study, Korean emails will be analyzed based on the collected email corpuses that were written in Korean among Koreans who was living in Korea. The corpus of 45 emails was collected through a Discourse Completion Test (DCT) from 15 Korean native speakers based on three different situations. Situation \#1 was to write an e-mail to an older person. Situation \#2 was to write an email to an equal aged person, and Situation \#3 was to write an email to a younger person. The main target of the experiment was to examine how language use in email discourse changes according to each differently aged person. The results of the three different sets of emails are compared with each other, with the initial assumption that there would be clear differences in language use.

Crucially, the experiment was based on imagined situations and people. These emails were not actual correspondence. The assumption was that if there were two different aged persons who corresponded through sending and receiving emails, those emails should show clear different use of language. For example, the result of situation \#1, in which a writer sends an email to a senior professor, should be an example of a maximum age complex case. The result of sending emails to an equal-aged person should be neutral age complex case. The result of sending emails to a younger-aged person should be the minimum age complex case. This study assumed that there would be clear differences 
in use of language based on [ \pm age] between younger Korean emailers and older Korean emailers.

In conclusion, this study is based on the interdependent relationship between culture and language as reflected in the different uses of language among Korean [tage] groups of people. Therefore, the present study will contain descriptive information of Korean culture and language behaviors of Korean people. And then there will be the discussion of research methods and present analysis of the data from the experiment. Results of the experiment in email language use will show that there is a normative honorific system between [+age] and [-age].

\section{Language and Culture}

Culture exists in a close relationship with language, in that culture helps the users of a language govern and define the conditions and circumstances under which various messages may or may not be sent, noticed, or interpreted; indeed, cultural patterns and customs are sometimes explicitly encoded in a language (Salzmann, 2014; Gumperz, 1996; Sherzer, 1987; Hymes, 1974). In the examination of the distinctive cultural behaviors of Korean language users, the present study brings out Koreans' honorific culture honoring the older people by the younger people, which I argue is a key to Korean culture, encoded in Korean language and reflected in Korean's use of language. In other words, Koreans' use of language shows a peculiar behavior when it is used toward a [+power] person by a [-power] person.

\section{Ageism in Korean Culture}

Although, in the individualist's view, Koreans' changing linguistic forms according to age differences of recipients may be considered as an unnecessary social behavior, it is an important social performance to keep their society harmonious in their belief. For example, English speakers also consider the hearers' age in their conversation, but these considerations are very differently demonstrated in their grammar and lexicon from those of Korean speakers. Koreans show grammatical and lexical change in their language use according to different [ \pm age] recipients, considering [+age] as social power among the interlocutors, in more highly nuanced ways than available to English speakers. Thus, this present study shows that Korean honorification culture is embedded in verbal communication across various social relationships on [+age] differences among Korean interlocutors, especially in linguistic feature use. In their using honorifics, Koreans need to find proper linguistic forms of expression according to the age-related social statuses of their interlocutors. Therefore, when they use the chosen forms, the cultural values behind those forms are revealed.
Tudor (2012) and Anderson (2003) claim that Korean culture is generally more collectivistic and less individualistic than American cultures. People in collectivistic cultures are likely to live together as a large family unit or tribe, whereas people in individualistic cultures tend to live alone or in smaller groups such as the nuclear family. Group decisions are not as important as personal judgments in the U.S., while the opposite is true in Korea. Specifically, Korean collectivism has been nurtured by Confucianism - the teaching of Confucius, who stressed the importance of social harmony through hierarchical social relationships. For that reason, Korean juniors are encouraged to show respect towards their seniors. When the junior interlocutor does speak to the senior, the speech that the junior uses should contain honorifics which linguistically encode Koreans' socio-cultural structures. For more than 2000 years after Confucius' teaching, many Koreans have continued to believe that their social world is hierarchical; this belief constitutes an important aspect of their culture which is reflected in their language. Korean language encodes social structure through honorifics, and Koreans habitually use honorific expressions reflecting their habitual thoughts about social power, especially relative "age".

It is always important for Koreans to know first who is older among interlocutors or people discussed in a topic. The appropriate linguistic forms must be chosen according to the hierarchy. On the other hand, it is not so important to know who is older among siblings in English speaking culture. English speakers do not encode "age" of interlocutors or people, unless age is itself a topic of conversation. This entrenched, hierarchical social relationship is reflected in Korean linguistic patterns that feature a complex honorific system that reinforces a normative type of politeness - a sort of a socio-cultural indexing. Korean normative politeness can be expressed with grammatically and lexically encoded forms, honorifics, which are lexico-grammatical patterns that encode relations between the speaker and the addressed recipient.

\section{Linguistic Patterns of Honorifics}

Korean personal pronouns encode traditional Korean social hierarchy (Sohn, 2001). For example, there are two different first person pronouns in Korean: cher/chey and nah/nae. Both of them mean "I" in English, but the former cher/chey is to be used by a younger person to an older person to be polite. The latter nah/nae is mostly used by an older person to a younger person. However, the latter case is a little bit more complicated than the former because it can also be used among equal-aged interlocutors and by a younger person to an older person in a close relationship or a younger person to an enemy in an extremely distant relationship. 
Korean second-person pronominal forms are more complicated than the first-person forms. For example, erusin (an elder) can be used to address an elderly person, while nuh (you) can be used plainly to a much younger person. There are four second person pronouns (e.g. nuh/ney, dangshin, chaney, and chaki), but none of them are used in addressing an elder. The address form, erusin (elder), is not originally a pronoun but a noun, although it is now used as a pronoun. One of the salient features of Korean second-person pronouns is that there is no appropriate pronominal form for a recipient who is older than the speaker. In such cases, pronouns are frequently replaced by other Noun Phrases (nominal substitutes) such as kinship terms, including samchon (uncle), halmuhni (grandmother), and ahburchi (father), or professional titles such as seonsaeng-nim (honorable teacher), sachang-nim (honorable company boss), and koyswu-nim (honorable professor). Therefore, speakers of Korean must be very careful in using honorifics so as not to be rude, especially to any elders and older hearers.

Korean honorifics also include a set of hierarchical address-reference terms which should be sensitively chosen and used according to differences in age and/or social status between the speaker and the addressed recipients and/or referents, as seen in Table 1. To address a professor or a father honorably, Koreans have to call him kyoswunim (honorable professor) or ahburnim (honorable father).These terms comprise the general title kyoswu (professor) or kinship term ahburgi (father)
+ the highest honorific title, -nim, which means honorable. A lower honorific for a teacher is seonsaeng (teacher) and, for a father, ahburgi (father); these eliminate the highest honorific title nim. Surname Lee + Professional title like parksa (Ph.D) is a less exalted honorific expression than the previous expressions. In this case, the speaker may be an older person than the recipient or around the same age as the addressee. Stepping down to the next level of honorific address is the use of a person's full name Hyunwook Kim+the secondlevel honorific title -ssi (Mr.-although even the English honorific titles, Mr./Mrs./Ms., are not hierarchical, indicating instead gender roles and marital status). Below this is Surname Kim+the third-level honorific title $\boldsymbol{k w u n}$ or yang, for which there is no obvious English equivalent. Less honoring still is Surname Kim+Given name Hyunwook. The least honoring expression is Given name Hyunwook+plain vocative particle $-\boldsymbol{a} / \boldsymbol{y} \boldsymbol{a}$, which does not have an English counterpart. Speakers must select among these hierarchical expressions, taking into consideration the age and social status of both the speaker and the recipient. As seen in Table 1 below, when the level of honor goes up, the apparent age or social power of the speaker, as reflected in language, goes down. According to the speaker's choice, the recipient can engage the same habitual system to determine whether he or she has been honored or dishonored by the speaker, regardless of the speakers' real thoughts.

Table 1. Korean Hierarchical Address-reference Terms*

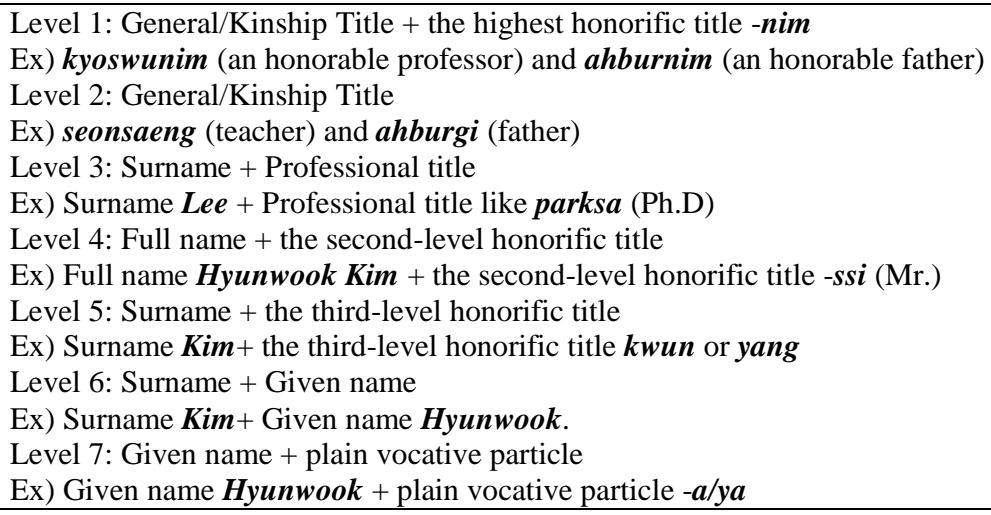

*Refer to the abbreviation terms at the Appendix A before the reference in this paper.

Certain Korean nouns, predicates (verbs), and particles also have variants that can be used to show deference toward [+age] people by [-age] people as well as to show the humility of the speaker. Although those honorific nouns, predicates, and particles exist only in a limited set, they are used regularly in communication between younger people and older people in Korea. In addition, Korean has a very productive suffixal device for subject honorification that appears right after a predicate stem. The two main bodies of Korean honorifics consist of addressee honorifics (the perspective of the speaker/writer toward the addressee) and referent honorifics (the perspective of the speaker/writer toward the referent). Addressee honorifics are usually marked in the address term and predicate suffixes. Referent honorifics can be divided into subject, object, and oblique features such as dative, locative, goal, and source honorifics. The nominals that function grammatically as subject, object, and oblique can have deferential forms that generate deferential predicates. Along with the 
levels of address reference terms, Korean has various speech levels of subject and addressee honorification in relation to the predicates. The representative speech levels are "plain," "intimate," "polite," and "deferential," arranged from the lowest to the highest level of the addressee or subject honorification as seen in 1) below.

1) Declarative Sentence:

\begin{tabular}{|c|c|c|}
\hline & $\begin{array}{l}\text { Plain: Nah-nun } \\
\text { I-NOM } \\
\text { I eat lunch. }\end{array}$ & $\begin{array}{l}\text { murknun-da. } \\
\text { eat-RE. }\end{array}$ \\
\hline Intimate: & $\begin{array}{lll}\text { Nah-nun } & \text { chumsim } & \text { murk- } \boldsymbol{a} \\
\text { I-NOM } & \text { lunch } & \text { eat-IE. } \\
\text { I eat lunch. } & & \end{array}$ & \\
\hline Polite: & $\begin{array}{l}\text { Cher-nun } \\
\text { I-HFPP-NOM } \\
\text { I eat lunch. }\end{array}$ & $\begin{array}{l}\text { murka-yo. } \\
\text { eat-PE. }\end{array}$ \\
\hline Deferential: & $\begin{array}{l}\text { Cher-nun } \\
\text { I-HFPP-NOM } \\
\text { I eat lunch. }\end{array}$ & $\begin{array}{l}\text { murksu-pni-da. } \\
\text { eat-AHSF-DE. }\end{array}$ \\
\hline
\end{tabular}

As seen in 1), a Korean declarative sentence can convey four different messages and meanings through four different speech levels that can be constructed by using four different declarative enders: regular plain ender (RE), intimate ender (IE), polite ender (PE), and deferential ender (DE). The regular plain form can be used to a person younger than or junior to the speaker, indirectly meaning that the speaker is [+age] to the addressee or may be in a [-distance] relationship with the addressee. The intimate form of ender is good to use toward an equal-aged person or younger friend. In [-distance] relationship, it is often found that a [-age] person uses this intimate form even to a [+age] addressee as an in-group member who has a kinship relationship. Unlike the deferential ender, the polite ender is used to imply that although the speaker does not give deference toward the addressee, the speaker is polite toward the addressee, revealing the message that the speaker perceives relatively more [-distance $]$

2)

Kyoswu-nim, ahburnim-kkeseo
Professor-HTa, father-HTa-HNOM

chinchi

meal-HN

Professor, my father is having a meal.

Like number agreement in English, Korean has honorific agreement which is a system of using the honorific suffixes $-(\boldsymbol{u}) \boldsymbol{s i}$ and/or $-\boldsymbol{p}(\boldsymbol{n i})$ in relation to their triggers (Sohn, 2001). For example, as in 2) above, these suffixes must be attached to the predicate if the subject or addressee of the predicate is a person who deserves the speaker's deference. This is illustrated through the subject ahburnim (father) and the addressee kyoswu-nim (professor) in 2) - when these persons are honored by the speaker, the suffixes - $(\boldsymbol{u})$ si and -(su)pni should be inserted in the plain predicate form, chapswuda (eat relationship than when s/he uses the deferential ender.

The verb murkda (eat or have) is a plain predicate appropriately directed toward a younger recipient, which should be changed into the corresponding deferential predicate like chapsw-usipni-da toward an older recipient as seen in 2) below. It is interesting that many Koreans habitually add the honorific suffixes $-(\boldsymbol{u}) \boldsymbol{s i}$ and $-\boldsymbol{p}(\boldsymbol{n i})$ into the deferential predicate chapswusda, which does not require any affixes because the verb itself already has honor meaning. But through inserting the suffixes $-(\boldsymbol{u}) \boldsymbol{s i}$ and/or $\boldsymbol{- p}(\boldsymbol{n i})$ the verb can indicate even greater respect toward a subject or an addressee. Thus, these honorific suffixes - $(\boldsymbol{u})$ si and $\boldsymbol{p}(\boldsymbol{n i})$ are powerful. Any plain verb can be made deferential by inserting honorific suffixes associated with the addressee or the subject that the speaker wants to honor.

\section{chapsw-usi-pni-da. eat-HPre-S\&AHSF-DE.}

or have) without omission. Unlike the subject honorific suffix -(su)pni, the addressee honorific suffix- $(\boldsymbol{u}) \boldsymbol{s} \boldsymbol{i}$ can be replaced by a polite form of predicate like chapswuseyyo where -(su)pni- is somewhat reshaped into sey. Concurrently, the ender of the sentence is transformed into a deferential form like -usipnida in 2) from the plain predicate ender form $-\boldsymbol{d} \boldsymbol{a}$.

When a speaker of Korean uses honorific markers in his/her speech to a recipient who is older than the speaker, the speaker shows honor to the recipient by honorific. Thus, Korean speakers 
habitually and unconsciously use these honorifics with the assumption that all people in the world share the same ideas. Although the honorific system is complex, Korean speakers and recipients are accustomed to automatically considering aspects such as relative [+age] and/or [tpower]. When an older recipient does not hear the level of honorific expression that s/he expects, there can be a conflict with a younger speaker because the older recipient perceives that $\mathrm{s} / \mathrm{he}$ is not respected by the younger speaker. It is often very serious.

Thus, given the cultural relations cultivated within a collectivist social background, Koreans, especially younger persons, have developed a peculiar communication style, honorification, in their lexico-grammatical use. Specifically, this tendency or pattern of communication has generated a unique Korean communication culture. Consequently, this study will discuss the Korean honorific culture that indicates Koreans' thoughts about age as reflected in Koreans' linguistic features in terms of [ + age] relationship, which may or may not be found in those of speakers of other languages. The venue of this discussion will be on the Korean email discourse in status-unequal and status-equal sender and receiver relations.

\section{Email Communication and Culture}

Since internet communication is modern and originated in the west, we might expect that Korean internet communication would not exhibit distinctive and intricate aspects of Korean language and culture, especially grammar, such as its honorifics system. According to the case study that Chen (2006) has done, an L2 (Second Language) English learner has to struggle to overcome L1 (First language) cultural influence until s/he acquires a proper level of L2 email communication, especially with [+age] and/or [+power] people such as her professor. As an Asian, the L2 English learner revealed several pragmatic problems such as unclear and delayed purpose statements with many irrelevant details. One of the conclusions that Chen (2006) made is that the development of the L2 learner's language use in emails with a statusunequal person takes a long time because it is neither an easy nor a simple process.

Bjørge (2007) studied the level of formality shown in the emails that international students sent to academic staff. She argues that factors such as age and position of authority come into play in email discourses. The starting point of her study is to revisit Hofstede's previous empirical study of national average scores concerning attitudes towards asymmetry of power (2001). The concept of power distance (PD) is "the extent to which the less powerful members of institutions Hofstede's and organizations within a country expect and accept that power is distributed unequally," and particularly, the extent to which older people are respected and even feared by younger people in a high PD culture (2001, p. 98). Hofstede (2001) relates his PD dimension to educational systems. According to him, high PD educational situations demonstrate a teacher-centered mode where a teacher is not criticized by students. In contrast, in low PD educational situations, teacher-student relationships approach equality, such that the teacher can be challenged by students at any time. Bjørge (2007) applies the theory of PD dimension into her study to explain linguistic behaviors shown in emails written by members of these two kinds of cultural groups.

Specifically, Bjørge (2007) examines the forms of address and complimentary closes used in English emails by international students at the Norwegian School of Economics and Business Administration. According to her classification of low and high PD countries, the US belongs to low PD culture, whereas Korea is a high PD culture. She compares and contrasts levels of formality/informality between those two different cultural groups. In terms of the range of formality and informality, she considers Dear+Honorific/Title+Surname, or Dear Sir/Madam as formal and Hi (+First Name) or First Name only as informal while Dear+First Name is neutral. The results show that students from high PD culture are considerably more likely to include a formal greeting than those from low PD cultures. In choice of formal greeting, Korean students show formality $100 \%$ of the time, while US students show it only $58 \%$ of the time. The results of the complimentary close in the formal/conventional to informal/personal range are similar. Korean students show formality $100 \%$ of the time once again, while the US students show it $33 \%$ of the time. Bjørge's (2007) conclusion is that there is considerable variation when it comes to the choice of greetings and closings in email discourses among these two different cultural groups. Bjørge's study (2007) has an interesting finding, namely, that there is a cultural factor that causes speakers to use language differently, especially when that language is English.

However, her study does not explain clearly why and how the cultures of non-native English speakers can cause them to use English differently than English native speakers. For example, except for the explanation that Korean language belongs to High PD culture, she does not discuss how High PD culture affects the way that the Korean emailers think and how their different thought processes affect their different use of Korean language in email correspondence. Her study is about Koreans' use of English, not Koreans' use of Korean in email discourse. Moreover, because her study is confined to only the choice of greeting and closing in email discourse, it is too narrow and partial to provide a full picture of the relationship between cultural patterns and linguistic patterns. This present study moves forward from Bjørge while attending to her 
suggestions for further research, especially the age factor that has a huge influence on Korean culture and linguistic property; that Korean language use depends on social and cultural context, and that Korean culture is embedded in particular instances of use, as shown when email senders and receivers are involved in an unequal-status communication.

\section{Research Questions}

The email discourse is expressed in written form according to the nature of spoken language, so it can be a good source for researchers to study cultural features in language. Indeed, researchers (Spilioti, 2011; Bjørge, 2007; Chen, 2006) have found important cultural factors in language and language use in studies of email discourse. However, the study of email discourse in relation to Korean language has not been done. It is a relatively new field.

This study focuses on the discussion of lexical and grammatical features of Korean language use in a corpus of emails written in Korean with the following research questions: (1) Is Korean honorific culture connected to the use of Korean language based on [tage] complex in Korean email discourse? (2) If so, do the results of the current experiment support the assumption that Koreans' usage of Korean honorifics are significantly related to each other according to [ + age] difference?

\section{METHOD}

The main task of this study was to deal with Korean's honoring cultural behavior. I assumed that Korean honorification is culturally embedded in Koreans' use of linguistic forms, reflecting their concept of [+age] as [+power] as displayed in the delicate and complex honorific system. The connections between age, human relationships, and language use were assumed to be handled by Koreans' cultural habits in their daily life. To illustrate this, I undertook an experiment to examine the close relationship between language use and cultural view. This experiment elicited maximum and minimum levels of Korean honorification in the linguistic patterns because the sender would experience cultural pressure in two ways: the normative cultural pressure that came from writing an email to a [+age] and/or [+power] person like a senior professor, and the face-threatening task of the message - making a request. On the other hand, the minimum cultural pressure case would be seen in the emails sent to close, younger friends. When the age of a requestee is younger, the Korean senders might perceive much less pressure to use honorification than when addressing an older person. The hypothesis underlying the experiment was that we would find mechanisms of Korean language use in the email messages that would reveal the close relationship between Koreans' hierarchical sociocultural system and their choice of language use in emails.

\section{Data Collection}

For the experiment, variables were manipulated to be the same for all participants. The task assigned to all participants was to write an email in Korean to [+age] recipients. Fifteen Korean emailers (9 females, 6 males) wrote a total of 45 emails. All 15 Korean participants were college students who lived in South Korea in the age range of 21-25 years old. They were asked to write three emails according to a written discourse completion test (DCT) with 3 different situations. The 3 different situations were controlled to examine the senders' language use towards 3 different status people: [+age], [=age], and [-age] people, as follows.

$$
\begin{array}{ll}
\text { Situation } \# 1 \text { - asking a senior professor for an extension } & {[+ \text { age }]} \\
\text { Situation } \# 2 \text { - asking a friend to come to a library with a class-note } & {[=\text { age }]} \\
\text { Situation } \# 3 \text { - asking a younger friend for help in moving } & {[- \text { age }]}
\end{array}
$$

One of the three situations involved a person of younger status asking someone of [+age] status, one situation involved a person of equal status asking someone the same age [=age], and the last situation involved an older person asking someone of a younger status. Note that all three senders in the three different situations were the same person; there were no replies for the senders' emails because the receiver was not a real person. I would examine how differently each person used his/her language towards those different aged receivers. The lexical and grammatical features reflecting Korean honorific culture in the emails were as follows: personal pronouns, address-reference terms, honorific nouns, honorific predicates, honorific particles, subject-and addressee-honorific affixes, polite ender -yo, deferential enders, plain enders, and abnormal enders. I expected that all Korean emails sent to [+age] persons would show differences in lexical and grammatical levels from those sent to [-age] or [=age] persons.

The following is one of the three situations for which the participants were supposed to write an email:

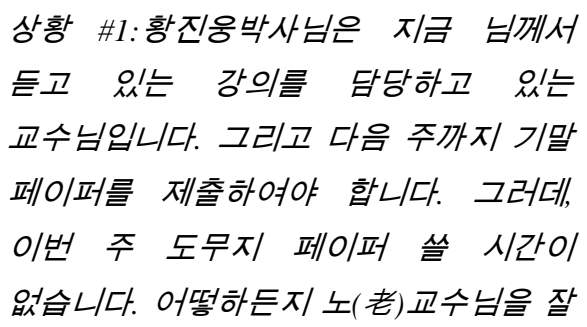


설득하여 페이퍼 제출 마감시간을 늘려야

하는 상황입니다. 그렇다면, 어떻게 부탁의 메시지를 담은 이메일을 쓸 수 있을 까요?

Situation \#1: Please, imagine that Dr. Walter Smith is a senior professor who gives a lecture in your class. You have a paper due in his class next week. However, you will be very busy this week and don't have any time to write it. You may really want to request an extension. So, you may have to write an email to him right now. How do you request an extension through email?

\section{RESULTS AND ANALYSIS}

As we see below, Table 2 is based on situation \#1, in which the senders of the emails were younger than the imaginary receivers. While the average sender's age was in the 21 to 25 age group, the imaginary receiver could be assumed to be over 40 , because the prompt suggested that senders consider the recipient a "senior professor." The situation is that the [-age] student senders had to request an extension of their paper due date from the [+age] professor. Therefore, the results of situation \#1 below will demonstrate that a [-age] person may express cultural pressure toward a [+age] person.

Table 2. Situation 1: asking a senior professor for an extension [+age]

\begin{tabular}{|c|c|c|}
\hline Linguistic Features & $\mathrm{F}$ & $\%$ \\
\hline \multicolumn{3}{|l|}{ Personal pronoun } \\
\hline \multicolumn{3}{|l|}{ First person pronoun } \\
\hline humble form : Cher/chey (I) & 13 & 87 \\
\hline plain form $\quad$ : Nah/Nae (I) & 0 & 0 \\
\hline Omission & 2 & 13 \\
\hline \multicolumn{3}{|l|}{ Second person pronoun: } \\
\hline Plain form; Nuh/Ney (you ） & 0 & 0 \\
\hline Replacement by GT/PT + HTa (you) & 15 & 100 \\
\hline \multicolumn{3}{|l|}{ Address-reference term } \\
\hline \multirow{4}{*}{$\begin{array}{ll}\text { Formal: } & \text { (Dear) }+ \text { GT + FN/SN } \\
& \text { FN + GT/PT + HTa: } \\
& \text { PT + HTa (Kyoswu-nim [hon. professor] }) \\
& \text { GT + HTa (Paksa-nim [hon. Dr.]) }\end{array}$} & 0 & 0 \\
\hline & 6 & 40 \\
\hline & 9 & 60 \\
\hline & 0 & 0 \\
\hline Informal: Hey + GT + FN/SN & 0 & 0 \\
\hline Honorific Nouns: & 15 & 100 \\
\hline Honorific Predicates: & 15 & 100 \\
\hline durida (give) & 9 & 60 \\
\hline cheychulhada(submit) & 6 & 40 \\
\hline \multicolumn{3}{|l|}{ Honorific Particles: } \\
\hline kkey (dative/locative/goal) & 8 & 53 \\
\hline kkeseo (nominative) & 7 & 47 \\
\hline both & 5 & 33 \\
\hline omission of both & 5 & 33 \\
\hline \multicolumn{3}{|l|}{ subject-and addressee-honorific affixes } \\
\hline subject honorific suffix $-(u)$ si (sy or sey) & 15 & 100 \\
\hline addressee honorific suffix $-(\boldsymbol{s u}) \boldsymbol{p}$ & 15 & 100 \\
\hline both & 15 & 100 \\
\hline polite ender - yo. & 11 & 73 \\
\hline \multicolumn{3}{|l|}{ Deferential enders: } \\
\hline -(su)pnida, -(su)pnikka?, -sipsio, -(u)sipsida & 15 & 100 \\
\hline
\end{tabular}

F: Frequency; \%: percentage

As seen in the personal pronoun section in Table 2, when the Korean senders made a request to a senior professor, they were under cultural pressure, choosing humble forms in their use of personal pronouns. Out of a total of 15 participants, 13 people used the humble forms of the first person pronoun (FPP), cher/chey (I), to the professor in their emails, which is $87 \%$. None of the senders used the plain form of FPP to their professor, although there were 2 persons who did not use either the plain or humble form of FPP: $13 \%$. However, none of them used even the plain form of second person pronouns (SPP) such as nuh/ney or dangsin (you): 0\%. Instead of using SPP, the senders used a title such as paksanim (hon. Dr.) or Professional title (PT) Kyoswunim (hon. Professor): $100 \%$. Many Koreans used this replacement of pronominal terms by other Noun Phrases (NP) for SPP habitually, not even consciously, because this behavior is a deeply rooted and ingrained cultural habit in Korean. Thus, Professional title (PT) + -nim is a typical Korean way of addressing a second person instead of using the SPP, you, as many Americans do, although Koreans have a diversified set of second person pronominal terms (e.g. nuh/ney, chaney, chaki/dangshin, and gwiha). In the Korean 
cultural environment, people think that the person who uses the plain form of SPP, you, is older or of a higher rank than the person who hears it. The addressee is often of a lower rank than the addresser. If Koreans do not want to offend the addressee, they must use the SPP very cautiously.

In the case of Address-reference terms (ART) used toward the senior professor, only $40 \%$ of the Korean senders used the name of the professor. However, they did not use only General Title (GT) or name alone $(0 \%)$. When they used the name of the professor, it was the form of the full name plus General Title/Professional Title (GT/PT) plus the highest honorific title (HTa) -nim. They did not habitually drop the first level honorific title, -nim, which is like a suffix of GT/PT, as long as they had deference toward the professor. In contrast, $60 \%$ of Korean senders did not even use the name of the professor, addressing him as PT + -nim (Kyoswunim) without putting his name. This was specifically Korean behavior which contrasts with Americans who freely use their professors' names with GT/PT title. The Korean younger senders might choose to follow their home culture, knowing that the American way of addressing a professor can be used only among school colleagues or to a junior scholar by a senior scholar in an academic field in Korea.

Honorific nouns (HN) such as choeysong (apology), durim (giving), malsseum (words), cheychul (submission) were actively used among participants $100 \%$ of the time. The plain form of choeysong was miyan. Even though English has formal and informal words that express similar meanings, like apology and sorry, it is acceptable for a younger person to say I am sorry to an older person in the US. But in Korea, it is not appropriate for a younger college student to use miyan (sorry) or miyan hada (I am sorry) to a professor because it can imply that the speaker is not inferior to the hearer in a situation where the student is obviously younger or lower than the professor. The student risks being considered impolite and someone who does not have a cultural sense. Also, the word choeysong linguistically requires honorific affixes and enders on the predicate, while the word miyan is mostly followed by plain forms of sentence enders. This rule is not only controlled by grammar itself, but also by culture. The honorific noun, Durim (giving), is in the same vein. The formal word durim should be followed by honorific sentence enders, unlike its plain form chum. Many Sino-Korean words such as choesong (apology) or cheychul (submission) that are borrowed from ancient Chinese have been used primarily among educated or aristocratic people Koreans, while durim (giving) and malsseum (words) are not borrowed words but originated in Korea to be used toward an older person by a younger person or toward a master by a lower class of people to connote deference.

The plain verb forms of HN durim (giving) and cheychul (submitting) that were used $100 \%$ of the time in the experiment were chwuda (give) and neyda (submit), respectively. However, when they were used by a younger student to address an older professor, their shape was changed into the Honorific predicate (HPre) druida and cheychulhada $100 \%$ of the time. The enders of the honorific verbs druida and cheychulhada were automatically changed into honorific enders through cultural pressure mechanism when the younger sender perceived the pressure toward the older addressee, as will be discussed below along with honorific affixes. In the usage of HPres, affixes, and enders, Korean demonstrates the complex honorific system ingrained in its language, a system that European languages, including English, do not have. In the case of a young student sending an email to a senior professor in Table 2, honorific particles (HPar) appeared as either $\boldsymbol{k} \boldsymbol{k e y}$ (to), which was used for indication of a dative/locative/goal with deference, or kkeseo, which has no English counterpart to be used as nominative: $67 \%$ of the time. The plain forms of the HPar kkeseo are un/nun/i/ka. 10 out of 15 participants used either kkey or kkeseo in their email, because there were 5 people who omitted both (33\%). Even though there was $33 \%$ of omission of both, this did not mean that the senders failed to show deference towards the older professor. They just decided that those sentences did not need those honorific particles in their emails.

Even when the senders did not use HPars, all the sentences that the younger senders wrote in their emails contained subject-and addressee-honorific affixes (SAHA) to show deference to the older professor, as the senders were under pressure of culture that came from the age difference. In this way, the younger senders could save the older person's face and could keep harmony with the older receiver. As was expected, $100 \%$ of Korean emailers used the subject honorific suffix (SHSF) (u)si (sy or sey), as in the following sentence: "Kyoswunim, yozoom kunkangeun urtter-si-nchiyo?"(Professor, how is your health recently?). Also, the addressee honorific suffix (AHSF) -(su)p(ni)was used by $100 \%$ of participants. For example, there was a sentence, "Kyoswunim, chung-yohan putaki itt-supni-da." (Professor, I have an important asking.) Along with SAHSes, all the emails written based on situation \#1 had deferential enders (DE) that came after the SAHSes. Those DEs were as follows: -(su)pnida (declarative), -(su)pnikka? (interrogative), -sipsio,(imperative) and -(u)sipsida (suggestive).

Interestingly, $73 \%$ of the younger email senders chose the polite ender (PE), -yo, out of four representative speech levels - plain, intimate, polite, 
and deferential - along with the DE. Although they did not use any plain or intimate forms of sentence enders, they chose to use at least PEs which meant that the senders reduced the level of cultural pressure and showed that they were in a closer relationship with the receivers. $90 \%$ of all female participants in the study used PE, and $50 \%$ of all males in the study did this. This study has not found any other significant gender differences based on honorific usage, but the usage of the PE, $-\boldsymbol{y o}$, showed a significant difference between female and male email senders. It was assumed that the female students had a tendency to be friendly to the senior professor, using the PE, while the male students tried to keep distance from the professor, using mostly DE.

According to Hymes (1972), languages are not functionally equivalent because the role of speech varies from one speech community to the next. As Deborah Tannen (2005) mentions, each person's individual style is a combination of features learned through interaction with others (hence social) plus features developed differently in each culture. Perhaps the impression of individual style results from the unique combination and deployment of socio-culturally learned features in America or Korea.

The results of situation \#2 showed many differences from those of situation \#1 in the Korean emails. In other words, we can confirm the assumption that Koreans have cultural ideas about [ + age] people that English speakers or others may not share. The way that Koreans sent emails to [+age] people and the way that Koreans sent emails to [=age or -age] people were different. When they sent emails to [+age] people, they behaved as if the [+age] person had social power, so the language that they used towards the [+age] person contained honorific markers, words, and forms that they put away when they sent emails to [-age] or [=age] people. This move implies that the writers perceived the younger or same aged receivers as powerless. As we have discussed throughout this study, Koreans have the cultural pressure when they send emails to [+age] people but they do not or do not want to have that stress when they send emails to [-age or =age] people. Therefore, when they sent emails to their same-aged friends, they wrote emails as if they were more powerful than their friends were by not perceiving cultural pressure.

In Table 3, where the situation involved a sender asking his or her equal-aged friend to come to a library with a class-note, I assumed that there would be a little bit of cultural pressure. But the level of cultural pressure would likely be much less than that of situation \#1 (writing a request email to a senior professor). The results are shown as follows.

Table 3. Situation 2: asking a friend to come to a library with a class-note [=age]

\begin{tabular}{|c|c|c|}
\hline \multirow{2}{*}{$\begin{array}{l}\text { Linguistic Feature } \\
\text { Personal pronoun }\end{array}$} & \multirow[t]{2}{*}{$\overline{\mathrm{F}}$} & \multirow[t]{2}{*}{$\%$} \\
\hline & & \\
\hline \multicolumn{3}{|l|}{ First person pronoun } \\
\hline humble form : Cher/chey (I) & 0 & 0 \\
\hline plain form $:$ Nah/Nae (I) & 15 & 100 \\
\hline \multicolumn{3}{|l|}{ (table 6 con'd.) } \\
\hline \multicolumn{3}{|l|}{ Second person pronoun: } \\
\hline Plain form; Nuh/Ney (you) & 15 & 100 \\
\hline Replacement by GT/PT + HTa(you) & 0 & 0 \\
\hline \multicolumn{3}{|l|}{ Address-reference term } \\
\hline \multirow{4}{*}{$\begin{array}{ll}\text { Formal: } & \text { (Dear) }+ \text { GN + (SN) } \\
& \text { FN + GT/PT + HTa: } \\
& \text { PT + HTa (Kyoswu-nim [hon. professor] }) \\
& \text { GT + HTa (Paksa-nim [hon. Dr.]) }\end{array}$} & 0 & 0 \\
\hline & 0 & 0 \\
\hline & 0 & 0 \\
\hline & 0 & 0 \\
\hline \multirow{2}{*}{$\begin{array}{ll}\text { Informal: } & (\text { Hey })+G T(\text { friend })+a / y a \\
& (\text { Hey })+G N+(a / y a)\end{array}$} & 1 & 7 \\
\hline & 14 & 93 \\
\hline No address-reference term & 0 & 0 \\
\hline Honorific Nouns: & 0 & 0 \\
\hline & 0 & 0 \\
\hline durida (give) & 0 & 0 \\
\hline cheychulhada(submit) & 0 & 0 \\
\hline \multicolumn{3}{|l|}{ Honorific Particles: } \\
\hline \multicolumn{3}{|l|}{ Honorific: } \\
\hline \multirow{2}{*}{$\begin{array}{l}\text { kkey (dative/locative/goal) } \\
\text { kkeseo (nominative) }\end{array}$} & 0 & 0 \\
\hline & 0 & 0 \\
\hline \multicolumn{3}{|l|}{ Plain: } \\
\hline Eykey(seo)/Hantey (dative/locative/goal) & 1 & 7 \\
\hline Un/nun/i/ka (nominative) & 14 & 93 \\
\hline Both & 1 & 7 \\
\hline None & 1 & 7 \\
\hline
\end{tabular}

subject-and addressee-honorific affixes 
subject honorific suffix $-(\boldsymbol{u})$ si (sy or sey)

addressee honorific suffix $-(s u) p$

$0 \quad 0$

Deferential enders:

-(su)pnida, -(su)pnikka?, -sipsio, -(u)sipsida

polite ender $-y$ o.

0

Regular plain enders:

-da-ni/-(nu)nya? -kera/ura-cha $15 \quad 100$

Abnormal plain enders: $\quad 1500$

Casual Contractions of word or phrase:

12

F: frequency; \%: percentage

In this situation, there was a change of the first person pronoun into the plain form nah/nae $100 \%$ of the time. All 15 participants used the plain form of FPP as seen in Table 3. The usage of the SPP was also changed to nuh/ney in situation \#2 by $100 \%$, showing no replacement of GT/PT + HTa address form for the SPP.

In the ART section, the deferential formal address pattern, "dear + GN" was used by $0 \%$ among 15 participants. Rather, $7 \%$ of the emails showed the pattern, "Hey + GT(friend) + a/ya." Overall in situation \#2, 93\% of participants used informal ARTs such as, "(Hey) +GN + (a/ya)." The vocative particle $-\boldsymbol{a} / \boldsymbol{y} \boldsymbol{a}$ was popularly used in the emails; it implied an intimate relationship between sender and receiver, whether among close friends or when an older person addressed a younger person in a friendly manner. But this form can also have condescending connotations, because someone who uses this vocative particle might be of a higher status. Therefore, this form might not be used toward strangers or toward older persons in Korea.

In situation \#2, the emails did not show use of HNs (0\%). There were a couple of cases of using Sino-Korean terms in these emails, but the senders did not show deference with them As a result, no HPres were followed. There were also no HPars like -kkey or -kkeseo in the emails. In situation \#2, we see that the senders did not show deference to equal aged receivers; the senders used plain particles like -eykey(to)/hantey (from) for dative/locative/goal or $-\boldsymbol{u n} / \mathbf{n u n} / \mathbf{i} / \mathbf{k} \boldsymbol{a}$ for nominative by $100 \%$. The SAHAs were also absent in the emails and neither the DE or PE “-yo" appeared in any of the emails.

As we see in Table 3, plain enders were used in the emails sent to equal aged friends by $100 \%$. These sentence enders imply a cultural message related to [tage] that Koreans may not share with other language speakers. The users of DEs in a Korean email should not be older than the receivers; if they are, it may mean that the users want to give respect to the receiver regardless of age difference or because the sender does not know how old the receiver is. On the other hand, if a sender uses plain enders, the sender's email implies the extra nonverbal meaning that the exchange is free of cultural pressure, showing an intimate relationship with or condescending to the receiver regardless of age difference. It may, however, also imply that the sender is condescending to the receiver.
In addition, there were interesting findings in the emails' sign-offs in situation \#2. There were abnormal plain enders by $100 \%$ and casually contracted forms of words or phrases by $80 \%$ in the emails that the senders sent to their equal-aged close friends. The abnormal plain enders ended sentences improperly or incompletely, for example using maliya, -haseo or -deun. More than 20 different examples of abnormal enders (AE) were found in the emails written based on situation \#2. These abnormal sign-offs were morphologically different from the plain enders, which were - $\boldsymbol{d a}$ (declarative), -ni/-(nu)nya? (interrogative), -kera/ura (imperative), and -cha (suggestive), although the abnormal enders (AE) share the same meaning as these plain enders (PE). The use of these abnormal enders can mean more than just that the users perceive the exchange to be free from the pressure of [+age] complex cultural pressure. It implies, rather, more of either a condescending or an intimate attitude toward the younger or equal aged receivers. Koreans dare not use any of these abnormal enders to [+age] people unless they are purposely trying to anger the older receiver, because these enders are viewed as disrespectful in the Korean language use.

Also, there were many casual forms of contraction typically found in spoken language in the emails based on situation \#2. They included the use of -haenwatseo instead of haenouwatseo (have done), -hanundey instead of handa kureondey (do but), and -duluttsum instead of duluttsumyun (if you listened to). Technically, this language use is ungrammatical. But their use in the emails does not mean that the senders are illiterate people who do not know the correct grammatical expression. Only when they sent their emails to equal-aged or younger persons did they choose these forms of expression, because they were released from the pressure of culture. None of the people who wrote these expressions to their equal aged friends wrote the same ways in their emails to older professors. This fact shows another aspect of language use in relation to Korean culture of honorification.

As we examine the results of Table 4, based on situation \#3 where the senders wrote emails to ask a younger friend for help in moving, we see clear similarities among the results of situation \#2 and situation \#3. When older persons ask their younger friends for help, the older senders might also be 
constrained to use honorific expressions under only the pressure of imposition to the younger receivers. Nonetheless, according to the results of situation \#3, the older senders did not change their lexicogrammatical forms of expression in a deferential way due to imposition, something that we saw to be true in the emails sent to equal aged interlocutors in situation \#2. This means that even in the impositive situation of making a request, the honorific expression was not used to be polite or to reduce the degree of face threatening towards same aged or younger receivers in Korea. Korean Honorifics were normatively used between [+age] and [-age] people. Because of this hierarchical social system, it may be easier for an older person to ask a favor of a younger person than vice-versa in Korean society. The cultural pressure that comes from [+age] hierarchical social status is the main factor that elicits honorific expressions in Korea.

Table 4. Situation 3: asking a younger friend for help in moving [-age]

\begin{tabular}{lrc}
\hline \hline Linguistici Feature & F & \\
\hline Personal pronoun & & \\
First person pronoun & 0 & 0 \\
humble form : Cher/chey (I) & 13 & 87 \\
plain form : Nah/Nae (I) & 5 & 33 \\
Replacement by KT & 2 & 13 \\
Nuna(elder sister) & & \\
Hyung (elder brother) & 14 & 93 \\
Second person pronoun: & 0 & 0 \\
Plain form; Nuh/Ney (you) & & \\
Replacement by GT/PT + HTa (you) &
\end{tabular}

\begin{tabular}{|c|c|c|c|}
\hline \multicolumn{4}{|c|}{ Address-reference term } \\
\hline \multirow{4}{*}{ Formal: } & $($ Dear $)+\mathrm{GN}+(\mathrm{SN})$ & 0 & 0 \\
\hline & FN + GT/PT + HTa: & 0 & 0 \\
\hline & PT + HTa (Kyoswu-nim [hon. professor]) & 0 & 0 \\
\hline & GT + HTa (Paksa-nim [hon. Dr.]) & 0 & 0 \\
\hline \multirow{2}{*}{ Informal: } & $($ Hey $)+$ GT (friend) + a/ya & 0 & 0 \\
\hline & $(\mathrm{Hey})+\mathrm{GN}+(\mathrm{a} / \mathrm{ya})$ & 14 & 93 \\
\hline \multicolumn{2}{|c|}{ No address-reference term } & 1 & 7 \\
\hline \multicolumn{2}{|c|}{ Honorific Nouns: } & 0 & 0 \\
\hline \multirow{2}{*}{\multicolumn{2}{|c|}{$\begin{array}{l}\text { Honorific Predicates: } \\
\text { durida (give) }\end{array}$}} & 0 & 0 \\
\hline & & 0 & 0 \\
\hline \multicolumn{2}{|c|}{ cheychulhada(submit) } & 0 & 0 \\
\hline
\end{tabular}

\section{Honorific Particles:}

Honorific:

kkey (dative/locative/goal) $\quad 0 \quad 0$

kkeseo (nominative) $\quad 0 \quad 0$

Plain:

Eykey(seo)/Hantey (dative/locative/goal) $\quad 3 \quad 20$

Un/nun/i/ka (nominative) $14 \quad 93$

Both $\quad 2 \quad 13$

None of them $\quad 0 \quad r$

\begin{tabular}{lll}
\hline subject-and addressee-honorific affixes & & \\
subject honorific suffix - $(\boldsymbol{u})$ si $($ sy or sey $)$ & 0 & 0 \\
addressee honorific suffix $-($ su $)$ p & 0 & 0
\end{tabular}

addressee honorific suffix $-(s u) p \quad 0 \quad 00$

$\begin{array}{lll}\text {-(su)pnida, -(su)pnikka?, -sipsio, -(u)sipsida } & 0 & 0 \\ \text { polite ender -yo. } & 0 & 0\end{array}$

Regular plain enders:

\begin{tabular}{llrl}
$-\boldsymbol{d a}-\boldsymbol{n i} /-(\boldsymbol{n u})$ ny $\boldsymbol{a}$ ? - kera/ura $-\boldsymbol{c h a}$ & 13 & 87 & \\
\hline Abnormal plain enders: & 15 & 100 & \\
\hline Casual Contractions of word or phrase: & 13 & 87 & F: frequency; \%: percentage
\end{tabular}

First of all, the usage of FPP was similar in situations \#2 and \#3. Nah/nae (I) was used by $87 \%$ of the writers in situation \#3. Thirteen out of 15 participants used the plain form of FPP. In addition, the interesting finding about FPP usage in situation
\#3 was that FPP was also replaced by NPs, such as Kinship Title (KT) like nuna (elder sister)/hyung (elder brother), just as SPP was replaced by NPs in Table 1 based on situation \#1. Forty-six percent (46\%) of 15 participants who directed emails to 
younger close friends used the NP replacement of FPP. The plain form of SPP $\boldsymbol{n u h / n e y ~ ( y o u ) ~ w a s ~ s t i l l ~}$ used by $93 \%$ in the emails based on situation \#3. Even though only $7 \%$ of the emails in situation \#3 dropped the pronoun, this does not mean that these senders showed deference to the younger receiver. However, avoiding the form could make their relationship softer and cushion the request.

None of the older senders used HNs, HPres, or HPars in Table 4 in their emails. But $20 \%$ of older senders used plain particles like -eykey/hantey (dative/locative/goal), and $93 \%$ used $-\boldsymbol{u n} / \mathbf{n u n} / \mathbf{i} / \mathbf{k a}$ (nominative), and $13 \%$ used both. So the total number of particle users in Table 4 was actually $100 \%$. We can assume that none of the older senders used the SAHAs along with DEs. However, regular plain enders were used by $87 \%$, which means 13 out of 15 participants used regular plain enders, while abnormal plain enders were used by $100 \%$, which means all of the older emailers used at least one abnormal plain ender in their emails sent to younger receivers. The casual contractions of words or phrases were used $87 \%$ of the time. None of the Koreans in situation \#1 used either plain enders or abnormal enders; but in situations \#2 and \#3, the majority of the senders used either plain enders or abnormal enders by more than $80 \%$. This result may show that Koreans who send emails to older people use honorifics under cultural pressure, while Koreans who send emails to younger or equal aged people rarely use honorifics when under less cultural pressure.

There are a number of conclusions to be drawn based on the preceding experiment. First, we find that the language use for situation \#1 is extended and similar to standard written language, while the language use for situations \#2 and \#3 is simpler, shorter, and of relatively casual spoken variety. These findings were true among all the emails written based on the three different situations. Second, the emails to an older person from a younger person show various grammatical and lexical forms that reflect a close relationship between Korean language and culture. The younger senders are more likely to use honorifics in their email correspondence with older receivers under the pressure of a hierarchical relationship, and this complex is reflected on their use of language. So, according to the results of the experiment, age difference among interlocutors can stimulate Koreans to use honorifics and push younger addressers to honor older addressees in their written emails. Even in a heavily impositive relationship between older and younger people, the level of imposition does not affect the older people's use of honorifics toward the younger people. Yet the honorifics are always used by the younger people toward the older people. In other words, only the cultural pressure that comes from [ \pm age] complex triggers Koreans' use of honorifics.

\section{CONCLUSION}

This study examines a corpus of computer mediated discourse (i.e. email) to explore how Korean honorific culture particularly age complex is reflected in Korean email communication. In the experiment, this study documented and analyzed Korean emailers' linguistic indications of human relationships between [+age] and [-age] people. The results argue that Korean honorific culture, which reflects the hierarchical relationship between [+age] and [-age] people, affects Korean language in use. This reflection of [tage] social hierarchies in language is also one of the things that makes Korean different from English.

For the future study, it is suggested that along with [tpower] relationship, how [tdistance] relationship may affect Korean language use in relation with the use of (dis)honorifics. The idea that is originated from the results of this experiment should be compared to real-life email discourse as a calibration, measuring the different degrees of age complex in a corpus of actual Korean emails from diverse situations and among diverse people. The results of the experimental emails sent to an imaginary senior professor would be set up as the case reflecting the maximum level of age complex, and the results of the emails sent to an imaginary younger friend would be set up as the case of minimal age complex. These standards of maximum to minimum age complex could then be applied to the real-life emails that were collected to measure the various degrees of age complex between a father and a son, a seller and a buyer, or a doctor and a patient used in actual Korean emails.

Note that the emails used for the experiment were one-sided. Therefore, there is a limitation to examine the email features in the messages with responses. Based on the present finding, it will be interesting to apply this result to real-life email data. The suggestion for the further study is to analyze the close relationship among acquaintances in real life. In a close relationship, there is a tendency that a Korean can have less age complex. Then it will be interesting to see how this tendency will show in their language use especially in their emails.

\section{REFERENCES}

Anderson, P. A. (2003). In different dimensions: nonverbal communication and culture. In Larry A Samover \& Richard Porter $\left(10^{\text {th }}\right.$ ed.). Intercultural communication. (pp.78-86). CA: Wadsworth/Thomson Learning.

Bjørge, A.K. (2007). Power distance in English lingua franca email communication. International Journal of Applied linguistics. 17 (1), 60-80.

Chen, C.E. (2006). The development of email literacy: from writing to peers to writing to 
authority figures. Language, Learning \& Technology, 10(2), 35-55

Crystal, D. (1997). Encyclopedia of language $\left(2^{\text {nd }}\right.$ edition). New York: the Press Syndicate of the University of Cambridge.

Crystal, D. (2001). Language and the Internet. Cambridge: Cambridge University Press.

Crystal, D. (2005). The scope of internet linguistics. American Association for the Advancement of Science meeting, 18 February 2005; shortened version in The Western Mail, February

Georgakopoulou, A. \& Tereza, S. (2015). The Routledge handbook of language and digital communication. New York: Routledge Press.

Graham, S.L. (2007). Disagreeing to agree: Conflict, (im)politeness and identity in a computermediated community. Journal of Pragmatics, 39, 742-759.

Gumperz, J. J. (1996). The linguistic and cultural relativity of conversational inference. In Gumperz, John J. \& Levinson, Stepehn C. ed. Rethinking linguistic relativity. (pp. 374-406). Cambridge: Cambridge University Press

Hatipoğlu, Ç. (2007). (Im)politeness, national and professional identities and context: Some evidence from emailed 'Call for Papers.' Journal of Pragmatics, 39, 760-773.

Hofstede, G. (2001). Culture's consequences. $2^{\text {nd }}$ ed. Thousand Oaks, CA: Sage.
Hymes, D. (1972). Models of the interaction of language and social life. In J.J. Gumperz and D. Hymes (eds.), Directions in sociolinguistics: The ethnography of communication. (pp. 3571). New York: Holt, Rinehart, \& Winston.

Hymes, D. (1974). Foundations in sociolinguistics: an ethnographic approach. Philadelphia: University Pennsylvania Press.

Salzmann, Z., Stanlaw, J. \& Adachi, N. (2014). Language, culture, and society. Boulder: Westview Press.

Sherzer, J. (1987). A discoursed-centered approach to language and culture. American Anthropologist, New Series, 89(2), 295-309.

Sohn, H. (2001). The Korean language. New York: Cambridge University Press.

Spilioti, T. (2011). Beyond Genre Closing and relational work in Text Messaging. In Thurlow, Crispin \& Mroczek, Kristine (ed). Digital discourse: Language in the new media. New York: Oxford University Press.

Tannen, D. (2005). Conversational style. New York: Oxford University Press.

Thurlow, C. \& Kristine, M. (2011). Digital discourse: Language in the new media. New York: Oxford University Press.

Tudor, D. (2012). Korea - The impossible country. North Clarendon: Tuttle Publishing

\section{Appendix A: Abbreviations}

The following abbreviations are used to label the linguistic terms, especially for morphemes, employed in this study.

*: ungrammatical

AHSF: addressee honorific suffix

AE: abnormal ender

ART: address-reference term

CB: context building

DE: deferential ender

FN: full Name

FPP: first person pronoun

Future: future tense

GN: given name

GT: general title

HC: high context culture

HF: humble form

HFPP: humble form of first person pronoun

$\mathrm{HN}$ : honorific noun

HNOM: honorific nominative particle

hon.; honorable.

HONSF: honorific suffix

HPar: honorific particle

HPre: honorific Predicate

HSPP: humble form of second person pronoun

HTa: the first level honorific title/particle

HTb: the second level honorific title/particle
HTc: the third level honorific title/particle

IE: intimate ender

KT: kinship term

LC: low context culture

$\mathrm{N}$ : nunch' $i$

NA: not applicable

NOM: nominative particle

OBJ: objective particle

Par: regular plain particle

Past: past tense

PE: polite ender

PPar: possessive particle

PT: professional or occupational title

RE: regular plain ender

SFS: sharing fellowship stage

SAHA: subject-and addressee-honorific affixes

S\&AHSF: subject and Address honorific Suffixes

SHSF: subject honorific suffix

SN: surname

SPP: second person pronoun

TC: topic change

VPar: vocative particle 